\title{
Yetmiş Yaş Üstü Mide Kanserli Hastalarda Gastrektomi Sonrası Adjuvan Tedavi Etkinliği
}

\author{
Cemil BILIR ${ }^{1}$, Hüseyin ENGINN ${ }^{1}$, Özlem U. SÖNMEZ ${ }^{2}$, Sevil UYGUN İLIKHAN ${ }^{3}$, \\ B. Hakan BAKKAL ${ }^{4}$, Yasemin B.TEMI' ve Caner AKTAS ${ }^{4}$
}

${ }^{I}$ Bülent Ecevit Üniversitesi Tıp Fakültesi Medikal Onkoloji Kliniği, Zonguldak, Türkiye, cebilir@yahoo.com

${ }^{2}$ Sakarya Üniversitesi Ĕgitim ve Araştırma Hastanesi Medikal Onkoloji Kliniği, Sakarya, Türkiye

${ }^{3}$ Bülent Ecevit Üniversitesi Tıp Fakültesi Iç Hastalıklarl Kliniği, Zonguldak, Türkiye

${ }^{4}$ Bülent Ecevit Üniversitesi Tıp Fakültesi Radyasyon Onkoloji Kliniği, Zonguldak, Türkiye

\begin{abstract}
Özet
Mide kanseri cerrahi sonrası kemoterapi ve radyoterapi ile kür şansı olan ve iyi sağkalım sonuçları elde edilen bir hastalıktır. Yaşlı hastalarda adjuvan tedavi ve sonuçlar ile ilgili literatürde yeterli veri yoktur. $\mathrm{Bu}$ sebeple 70 yaş ve üzeri mide kanserli hastalarda adjuvan tedavi sonuçlarını inceledik. Retrospektif olarak 42 hasta dosyasını inceledik. 2005 ve 2012 yılları arasında 70 yaş ve üzeri toplam 42 mide kanserli hasta adjuvan tedavi aldı. Bu hastaların 20 tanesi kadın, 22 tanesi ise erkekti. Toplam \%65 hasta kemoradyoterapi, \%35 hasta ise sadece kemoterapi almışt1. Çalışmadaki hastaların \%48'i 6 kür kemoterapi ve radyoterapiyi tamamladı, \%21 hasta ise 5 kür kemoterapi alabilmişti. Dört hasta (\%15) radyoterapiyi toksisite nedeniyle tamamlayamadı. Dört hastada tedavi süresince hayatını kaybetti. Ortanca takip süresi 25 ay olup ortanca sağkalım 21 ay, progresyonsuz sağkalım 11,5 ay ve hastalıksız sağkalım ise 7 aydı. Regresyon analizinde tümör derecesi ve kemoterapi kür sayısı istatistiksel anlamlı olarak genel sağkalımla ilişkili bulunmuştur $(\mathrm{p}=0.001$ ve $\mathrm{p}=0.002$, sırasıyla). Sonuç olarak mide kanserli yaşlı hastaların \%48'i adjuvan kemoradyoterapiden, \%24'ü kemoterapiden fayda görmüşlerdir. Kemoterapi ve radyoterapiyi tamamlayabilen hastalarda bu fayda en yüksek orandadır. Kabul edilebilir bir toksisite gözlenen yaşlı hastalarda kemoterapi sonrası kolonu stimüle edici ajanlarla destekte yan etki riskini azaltmaktadir.
\end{abstract}

Anahtar Kelimeler: Mide kanseri, Yaşlı hasta, Adjuvan tedavi

\begin{abstract}
It is well known that gastric cancer (GC) has favorable outcome and survival with curative chemotherapy and radiotherapy following surgery. There is not enough literature regarding adjuvant treatment in elderly patients with GC. For this reason in this study we aimed to investigate the outcomes of adjuvant treatment of elderly (over 70 years) GC patients. We retrospectively investigated 42 elderly patients' hospital records. From 2005 to 2012, 42 gastric cancer (GC) patients older than 70 years had been treated with adjuvant therapy. The mean age of the patients were 74, 20 patients were women and 22 patients were male. Sixty five percent of patients received chemoradiation and remaining 35\% received only chemotherapy as adjuvant treatment. In the study population, $48 \%$ of patients completed all 6 cycles, $21 \%$ of patients had 5 cycles of chemotherapy. Four (15\%) patients have not completed radiotherapy due to toxicity. Four patients died during chemotherapy. Mean follow up period was 25 months after the adjuvant treatment. The median of overall survival was 21 months, progression-free survival was 11,5 months and disease free survival was 7 months of the study population. Multiple regression analysis revealed that, tumor grade, total dose of chemotherapy had statistically significant effecton the overall survival ( $P$ values were 0.001 and 0.002 respectively). Patients had favorable outcomes who adjuvant chemoradiotherapy or chemotherapy in elderly patients with gastric cancer. Patients who complete the all cycles of chemotherapy and radiation therapy had the most benefit from this treatment. Colony-stimulating agents following the chemotherapy reduce the risk of side effects in elderly patients and this is an acceptable toxicity profile.
\end{abstract}

Keywords: Gastric cancer, Elderly, Adjuvant treatment 


\section{Giriş}

Mide kanseri tüm dünyada akciğer, meme ve kolorektal kanserlerden sonra dördüncü en sik kanseridir. Kansere bağl1 ölümlerde ise ikinci sıklıkta yer almaktadır (Jemal ve ark., 2011). Erken evre mide kanserinde 5 yillık sağ kalım \%75 iken bu oran evre 2' de \%35'lere gerilemekte ve metastatik evrede ancak \%5'e ulaşabilmektedir (Agboola, 1994). Mide kanser insidansı da yaşla birlikte artış göstermektedir. Erkeklerde mide kanseri için ortanca yaş 70 iken kadınlarda 74'tür (Sanatia ve ark., 2011). Adjuvan tedavide en iyi yaklaşım konusunda tam bir fikir birliği olmamasına rağmen rezektabıl mide kanserli hastalarda sağ kalım üzerinde tedavilerin olumlu etkisi, zamanla anlaşılır hale gelmiştir. Gastrektomi öncesi 3 kür ve gastrektomi sonras1 3 kür kemoterapi mide kanserli hastalarda sadece operasyona oranla genel sağ kalımı uzatmıştır (MAGIC çalışması) (Cunnıngham ve ark., 2006). Bir başka çalışmada da gastrektomi sonrası kemoradyoterapinin sadece cerrahiye oranla sağ kalımı daha da uzattı̆̆ 1 ve nüks riskini azalttığı gösterilmiştir (Mcdonald ve ark., 2001). Mide kanserinin yaşla birlikte daha sı görülmesine karşın standart tedavi yaklaşımlarını oluşturan çalışmalarda çalışma topluluğunun büyük çoğunluğu 70 yaş altındaki hastaları içermektedir (Cunnıngham ve ark., 2006, Mcdonald ve ark., 2001). Bu nedenle yaşlı ve mide kanseri tanısı konulan hastalarda halen standart bir tedavi rejimi ve bu hastaları içeren randomize klinik çalışmalar mevcut değildir. Bizde bu amaçla kliniklerimizde tedavi almış, 70 yaş üstü mide kanserli hastaların adjuvan tedavi sonuçlarını sunmayı amaçladık.

\section{Materyal ve Metod}

$\mathrm{Bu}$ araştırma iki merkezde yapılmış bir çalışma olup retrospektif olarak dizayn edilmiştir. Bülent Ecevit Üniversitesi Medikal Onkoloji kliniğinde 2005-2012 yılları arasında ve Sakarya Üniversitesi Eğitim ve Araştırma Hastanesi Medikal Onkoloji kliniğinde 2010-2012 yılları arasında mide kanseri sebebiyle tedavi olmuş ve takibi yapılmış hastalar çalışmaya alınmıştır. Gastrektomi sonrası hastaların patolojik evrelerine göre adjuvan kemoterapi veya kemoradyoterapi planlandı. Kemoterapi olarak en s1k kullanılan kemoterapi protokolu; folinik asit $25 \mathrm{mg} / \mathrm{m} 21-5$ günlerde +5 -Fluorourasil $425 \mathrm{mg} / \mathrm{m} 21$ 5.günlerde 28 günde bir olarak verildi. Radyoterapi 2. veya 3. kür ile eş zamanlı olarak folinik asit 20mg/m2 1-4 günlerde + 5-Fluorourasil $400 \mathrm{mg} / \mathrm{m} 2$ 25-28.günlerde total 45-50.4 Gy (1.8 -2.0 Gy/gün) dozda uygulandı. Üç hastada ise kemoterapi olarak CFF rejimi uygulandı (cisplatin $50 \mathrm{mg} / \mathrm{m} 2$ 1.gün+ folinik asit $200 \mathrm{mg} / \mathrm{m} 2$ iv bolus 1 .gün, 5 - Fluorourasil $400 \mathrm{mg} / \mathrm{m} 2$ iv bolus sonras 1600 $\mathrm{mg} / \mathrm{m} 246$ saat sürekli infüzyon-14günde bir).

Patolojik evrelemede Amerika Kanser Ortak Komitesi (AJCC)' nin 2010 versiyonu kullanıldı. Evreleme amaçlı tüm batın ve akciğer tomografisi veya PET tomografisi uygulandı. Üçüncü veya dördüncü dereceden toksisite varlığında kemoterapi veya radyoterapiye ara verilerek doz ayarlamasına gidildi.

\section{İstatistiksel Analiz:}

Sayısal veriler ortalama-standart sapma olarak, kategorik veriler ise ortanca olarak belirtilmiştir. Normal dağılım gösteren veriler Student-t test ile, normal dağılım göstermeyen veriler ise MannWhitney U testi ile hesapland. Kategorik veriler ise Chi-kare ile hesapland1. İstatiksel analiz SPSS-17 programı ile yapılarak CI \%95 ve P $<0.05$ anlamlı olarak kabul edildi. Sağ kalım analizleri KaplanMeier metodu ile hesapland. Çok değişkenli verilerin değerlendirilmesinde Cox regresyon analizi kullanıld1.

\section{Bulgular \\ Genel Özellikler:}

Çalışmada toplam 42 hasta analiz edilmiş olup, 22 erkek hasta (\%52) kalan 20 hasta (\%48) ise kadındı. Çalışma grubunun yaş ortalaması 74 idi (70-83). Hastaların karakteristik özellikleri tablo 1' de belirtilmiştir. Çalışmada 15 hasta sadece kemoterapi almışken kalan 27 hasta kemoradyoterapi tedavis almıştı. Hastaların toplam kemoterapi sayısı 205 olup ortanca kemoterapi sayısı 5 (2-6)'idi. 20 hasta (\%48) tüm kemoterapi siklüslerini tamamlamışken 9 hasta ise 5 kür kemoterapi almıştı. 
Kemoradyoterapi tedavisini doz azatlımı yapılmadan ve tüm kürlerin hepsini tamamlayabilen hastaların sayısı 14'tü (\%33).

Tablo 1. Adjuvan tedavi alan hastaların genel özellikleri

\begin{tabular}{|c|c|}
\hline Özellik & N (\%) IR \\
\hline Hasta Sayı1 & $42(\% 100)$ \\
\hline Yaş & $74(70-83)$ \\
\hline \multicolumn{2}{|l|}{ Cinsiyet } \\
\hline Kadın & $20(\% 48)$ \\
\hline Erkek & $22(\% 52)$ \\
\hline \multicolumn{2}{|c|}{ ECOG performans durumu } \\
\hline 0 & $14(\% 33)$ \\
\hline 1 & $18(\% 43)$ \\
\hline 2 & $10(\% 24)$ \\
\hline \multicolumn{2}{|l|}{ Evre } \\
\hline 1 & $7(\% 17)$ \\
\hline 2 & $11(\% 26)$ \\
\hline 3 & $24(\% 57)$ \\
\hline \multicolumn{2}{|c|}{ Lenf nodu evresi } \\
\hline 0 & $12(\% 29)$ \\
\hline 1 & $14(\% 33)$ \\
\hline 2 & $12(\% 29)$ \\
\hline 3 & $4(\% 9)$ \\
\hline \multicolumn{2}{|c|}{ Histolojik derece } \\
\hline 1 & $16(\% 38)$ \\
\hline 2 & $16(\% 38)$ \\
\hline 3 & $10(\% 24)$ \\
\hline \multicolumn{2}{|c|}{ Kemoterapi rejimi } \\
\hline FUFA & $39(\% 93)$ \\
\hline CFF & $3(\% 7)$ \\
\hline \multicolumn{2}{|l|}{ Radyoterapi } \\
\hline Ald 1 & $27(\% 64)$ \\
\hline Almadı & $15(\% 36)$ \\
\hline \multicolumn{2}{|l|}{ Çalıșma sonu } \\
\hline Yaşayan & $26(\% 62)$ \\
\hline Ölen & $16(\% 38)$ \\
\hline
\end{tabular}

ECOG: Eastern Cooperative Oncology Group,

FUFA: Folinik asit ve fluorourasil kombinasyonu,

CFF: Sisplatin, Folinik asit ve fluorourasil kombinasyonu,

\section{Sağkalım Sonuçları:}

Bu çalışmada adjuvan tedavi alan 42 hastanın ortanca genel sağkalım (OS) süresi 21 ay (3-68) olup grafik 1'de belirtilmiştir. Progresyonsuz sağkalım süresi (PFS) ise 11,5 ay (3-68) ve hastalıksız sağ kalım süresi ise (DFS) 7 aydı (1-62). Multivaryant analizde genel sağkalıma etkisi olan faktörler kemoterapi kür sayısı $(\mathrm{p}=0.001)$ ve tümör derecesi $(\mathrm{p}=0.001)$ olup $\mathrm{R}^{2} \% 45$ 'ti (CI \%95 kabul edildi) (Tablo 2). Progresyonsuz sağkalımlada, kemoterapi kür sayısı ve tümör histolojik derecesi istatistiksel olarak anlamlı olacak şekilde ilişkili bulunmuştur (p değeri 0.001 ve 0.002 sırasıyla, $\mathrm{R}^{2} \% 52$, CI \%95). Kemoradyoterapi tedavisinin tüm kürlerini tamamlayan 14 hastanın ortanca genel sağkalımı 32 ay (768) iken tedavi siklüslerinin hepsini tamamlayamayan 28 hastanın ortanca sağkalımı ise 12 aydı (3-48) 
ve bu iki grup arasında istatistiksel olarak anlamlı fark mevcuttu ( $\mathrm{p}=0.003$, CI \%95). Aynı şekilde kemoterapi ve radyoterapisini tam dozda tamamlayan hastaların DFS'si istatistiksel olarak anlamlı derecede daha yüksekti (23 aya karşın 5.5 ay, p=0.0049, CI \%95). Takip süresince adjuvan tedavi alan hastalarda metastaz gelişme oranı \%12'di. Bu metastaz gelişen 5 hastanın ortalama sağ kalım süresi 23 ayd1.

Tablo 2. Gene să̆ kalıma etkileyen faktörler

\begin{tabular}{lccc}
\hline Değişken & $\boldsymbol{P}$ & HR & $\begin{array}{c}\text { CI (\%95) En kücük ve En } \\
\text { büyük değer }\end{array}$ \\
\hline Kür sayıs1 & 0.001 & 0.47 & $0.28-0.77$ \\
Tümör derecesi & 0.001 & 5.6 & $1.9-16$ \\
\hline HR:Hazard oranl, CI: Güven aralığl & & &
\end{tabular}

Kemoradyoterapi (KRT) ve kemoterapi (KT) alanlar karşılaştırıldığında ise genel sağkalım KRT grubunda 22 ay (3-68 ay), KT grubunda ise 15 ay (3-48) olup her 2 grup arasinda istatistiksel olarak anlam yoktu $(\mathrm{p}=0,27)$. Aynı şekilde PFS'da da iki grup arasında anlamlı fark yoktu (14 aya karşın 8 ay, $\mathrm{p}=0,15$ ). DFS'lerde de istatistiksel olarak anlamlı fark bulunamadı ( 8 aya karşın 4 ay, $p=0,19)$.

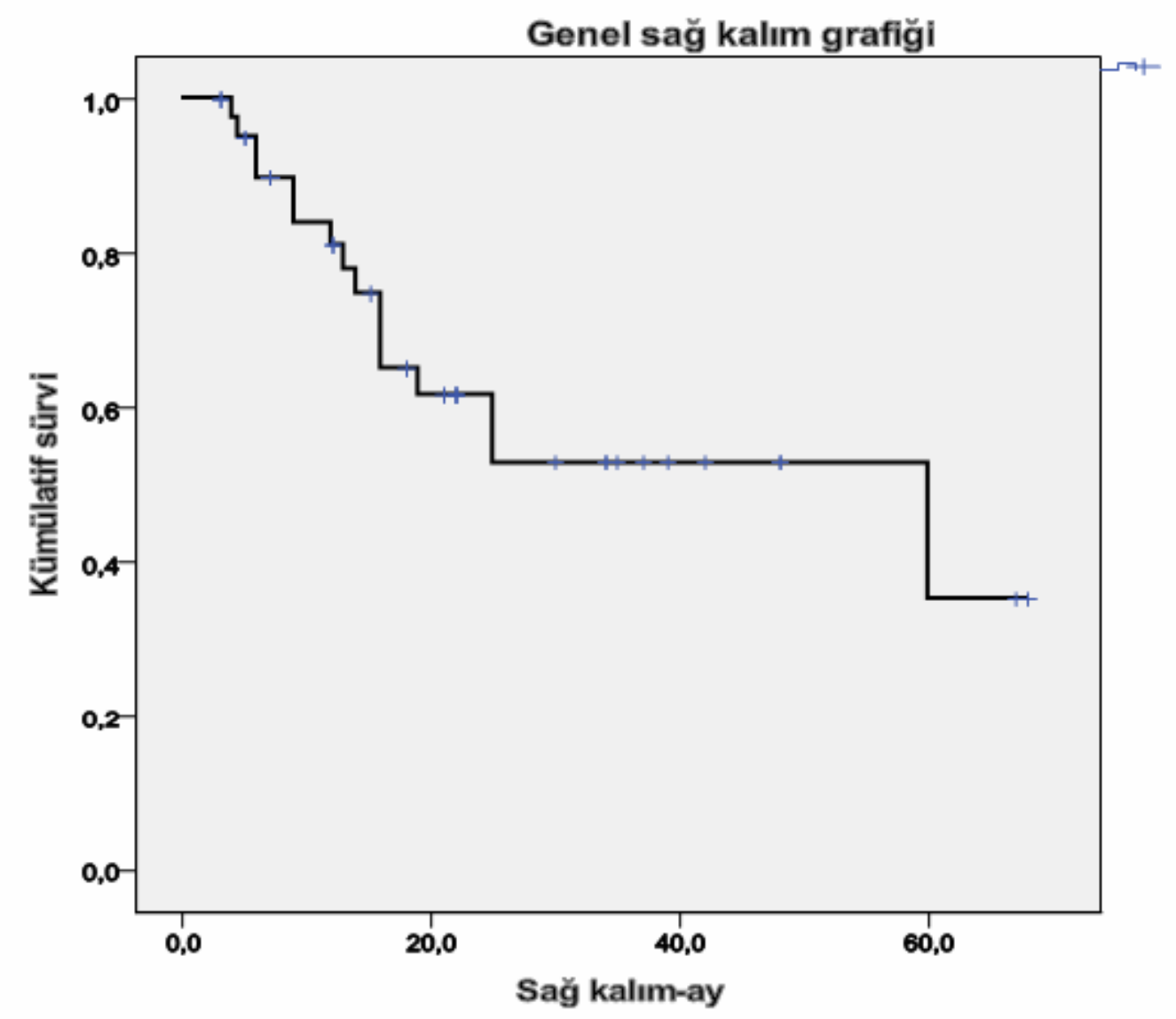

Grafik 1. Genel să̆ kalım grafĭgi 


\section{Toksisite Değerlendirilmesi;}

Kemoterapi süresince 4 hastada (\%9.5) kemoterapiye bağlı gelişen komplikasyonlar sebebiyle ölüm gerçekleşti. İki hasta septik şok, 1 hasta febril nötropeni ve 1 hastada akut miyokardial enfarktüs sebebiyle ölüm gerçekleşti. Kemoterapiye bağlı en sık görülen yan etki mukozit olup 1-2.derece mukozit 24 hastada (\%57) görülürken 3-4.derece mukozitse sadece 3 hastada (\%7) gözlendi. Diğer toksisiteler tablo 3 'te özetlenmiştir. Çalışma grubunda 4 hasta radyoterapisini tamamlayamamıştır. İki hasta 3.derece gastroenterit, diğer 2 hastada genel durumda bozulma sebebiyle radyoterapiye devam etmek istemediler.

Tablo 3. Kemoterapi süresince gözlenen toksisiteler ve siklı̆̆

\begin{tabular}{ll}
\hline Toksisite (derece) & N $(\%)$ \\
\hline Mukozit & $24(\% 57)$ \\
$1-2$ & $3(\% 7)$ \\
$3-4$ & $10(\% 23)$ \\
Nötropeni & $3(\% 7)$ \\
$1-2$ & $9(\% 21)$ \\
$3-4$ & 0 \\
Nöropati & \\
$1-2$ & $9(\% 21)$ \\
$3-4$ & 0 \\
KCFT bozukluğu & \\
$1-2$ & $4(\% 9,5)$ \\
$3-4$ & 0 \\
Trombositopeni & \\
$1-2$ &
\end{tabular}

KCFT: karaciğer fonksiyon testlerinde bozukluk

\section{Tartışma}

Yetmiş yaş üstü mide kanserli hastaların adjuvan tedavi sonuçlarının incelendiği çalışmamızda genel sağkalım, progresyonsuz sağkalım ve hastalıksız sağkalımla, kemoterapi kür sayısı ve tümörün histolojik derecesi istatistiksel anlamlı olarak ilişkili bulunmuştur. Yaşlı populasyonda kemoradyoterapi ile kemoterapi arasında genel sağkalım açısından anlamlı fark olmamakla birlikte kemoradyoterapi lehine bir avantaj söz konusudur.

Adjuvan kemoterapinin etkinliğini araştıran ve farklı sonuçlar gösteren birçok randomize çalışma ve metaanaliz yayınlanmıştır (Öksüz ve ark.,2010, Earle ve ark., 1999, Mari ve ark., 2000, Hermans ve ark., 1993). Bu çalışmaların çoğunda eski kemoterapi rejimleri kullanıldığı için tek başına adjuvan kemoterapi uygulaması standart bir tedavi olarak kabul görmemişti (Moertel ve ark., 1984, Hallissey ve ark., 1994). Geniş bir hasta sayısına sahip ve faz 3 randomize bir çalışma MacDonalds ve arkadaşları tarafından gerçekleştirildi (Mcdonald ve ark., 2001). Bu çalışmada evre 1b-4 mide kanserli olgularda operasyonu takiben kemoradyoterapi uygulanması ameliyat sonrası tedavisiz takip edilen kola göre lokal kontrol ve sağkalım üstünlüğü sağlamıştı (Mcdonald ve ark., 2001). Bu sonuçların yayınlanmasını takiben birçok merkezde gastrektomi sonrası kemoradyoterapi standart yaklaşım haline gelmiştir (Öksüz ve ark.,2010). Ancak, bu çalışmadaki en önemli handikaplardan biri kemoradyoterapi kolunda yan etki profilinin yüksek olmasıydı. Bu çalışmada yaklaşık \%20 hasta kemoradyoterapiyi tamamlayamamıştır (Mcdonald ve ark., 2001). Bizim çalışmamızda daha yaşlı bir hasta grubu olmasına karşın INT-0116 çalışmasından daha düşük bir oranda \%15 hasta radyoterapi tedavisini tamamlayamamıştı. Tek başına adjuvan kemoterapinin etkinliği ile de çelişkili eski çalışmalardan sonra faz 3 çalışmalar ve meta analizlerde fluoropiridin bazlı kemoterapinin tek başına cerrahiye göre ölüm riskinde \%18'lik bir risk azalmasına sebep olduğu gösterilmiştir (Paoletti ve ark, 
2010, Sasako ve ark., 2011). Bizim çalışmamızda da tek başına kemoterapi alan grup kemoradyoterapiye göre sağkalım açısından istatistiksel anlamlı bir fark göstermemişti.

Erişkin hastalarda adjuvan kemoterapi veya kemoradyoterapinin sağkalım avantajı sağladığı günümüzde kabul görmüş bir yaklaşımken yaşlı hastalarda böyle bir fikir birliği ve randomize klinik çalışma maalesef yoktur. Hoffman ve arkadaşlarının yaptı̆̆ 1 geriye dönük bir analiz çalışmasında 65 yaş ve üstü mide kanserli 1023 hasta incelenmiş (Hoffman ve ark., 2012). Bu çalışmada toplam 309 hasta kemoradyoterapi almışken, 583 hasta cerrahi sonrası tedavisiz takip edilmiş ve diğer 3. gruptaki 131 hastada kemoterapi veya radyoterapi tek başına almıştı. Bu 3 grupta da genel sağkalım açısından istatistiksel olarak anlamlı bir fark bulunamadı. Kemoradyoterapi grubunda ortanca sağkalım 25,4 ay iken takip kolunda 25,5 aydı (Hoffman ve ark., 2012). Ancak bu çalışmadaki hastaların yaklaşık \% 70’i T1-2 ve \%75 i N0-1 hastalar, yani erken evre mide kanserli hastalar çoğunluktaydı. Buda adjuvan tedavinin sağkalım avantajı sağlamamasının bir açıklaması olabilirdi. Bizim çalışmamızda ise erken evre mide kanseri yaklaşık \%20 oranında olup \%57 hasta evre3 'tü. İleri evre mide kanser hastalarının yüksek oranda olmasına karşın çalışma grubumuzun ortanca sağkalımı 21 aydı. Ayrıca kemoradyoterapi tedavisinin tüm kürlerini tam dozda alabilen 14 hastada ise ortanca sağkalım süresi 32 aydı. Bu süre yaşlı mide kanserli hastalarda adjuvan tedavi sonrası literatürde belirtilen en yüksek değerdir.

Yan etki açısından literatürle benzerlik görünmesi, yaşlı hastaların uygun bakım ve destek tedavileri ile adjuvan tedavi kürlerini daha rahat tamamlayacaklarını ortaya koymaktadır. Çalışmamızın zayıf yönleri ise, geriye dönük dosya taraması ile yapılan bir dizaynda olması ve kontrol grubunun olmamasidir.

Sonuç olarak mide kanserli yaşlı hastalar adjuvan kemoradyoterapi veya kemoterapiden fayda görmektedirler. Kemoterapi ve radyoterapiyi tamamlayabilen hastalarda bu fayda en yüksek orandadır. Kabul edilebilir bir toksisite gözlenen yaşlı hastalarda kemoterapi sonrası koloni stimüle edici ajanlarla destekte yan etki riskini azaltmaktadır.

\section{Kaynaklar}

Agboola O. 1994. Adjuvant treatment in gastric cancer. Cancer Treat Rev, 20(3):217.

Aminia A., Sanatia H. 2011. Complete pathologic response with combination oxaliplatin and 5-fluorouracil chemotherapy in an older patient with advanced gastric cancer. Anti-Cancer Drugs, 22:1024-1026.

Cunningham D., Allum W.H., Stenning S.H., Thompson J.N., Van De Velde C.J., Nicolson M., Scarffe J.H., Lofts F.J., Falk S.J., Iveson T.J., Smith D.B., Langley R.E., Verma M., Weeden S., Chua Y.J., Magic Trial Participants.2006. Perioperative chemotherapy versus surgery alone for resectable gastroesophageal cancer. N Engl J Med, 355:11.

Earle C.C., Maroun J.A. 1999. Adjuvant chemotherapy after curative resection for gastric cancer in non-Asian patients: revisiting a meta-analysis of randomised trials. Eur J Cancer, 35(7):1059-64.

GASTRIC (Global Advanced/Adjuvant Stomach Tumor Research International Collaboration) Group, Paoletti X., Oba K., Burzykowski T., Michiels S., Ohashi Y., Pignon J.P., Rougier P., Sakamoto J., Sargent D., Sasako M., Van Cutsem E., Buyse M. 2010. Benefit of adjuvant chemotherapy for resectable gastric cancer: a meta-analysis. JAMA, 303:1729.

Hallissey M.T., Dunn J.A., Ward L.C., Allum W.H. 1994. The second British Stomach Cancer Group trial of adjuvant radiotherapy or chemotherapy in resectable gastric cancer: five-year follow-up. Lancet, 343(8909):1309-12.

Hermans J., Bonenkamp J.J., Boon M.C., Bunt A.M., Ohyama S., Sasako M., Van De Velde C.J. 1993. Adjuvant therapy after curative resection for gastric cancer: meta-analysis of randomized trials. J Clin Oncol, 11(8):1441-7. 
Hoffman K.E., Neville B.A., Mamon H.J., Kachnic L.A., Katz M.S., Earle C.C., Punglia R.S. 2012. Adjuvant Therapy for Elderly Patients With Resected Gastric Adenocarcinoma. Cancer, 248-57.

Jemal A., Siegel R., XU J., Ward E. 2011. Global cancer statistics. CA Cancer J Clin, 61:69-90.

Macdonald J.S., Smalley S.R., Benedetti J., Hundahl S.A., Estes N.C., Stemmermann G.N., Haller D.G., Ajani J.A., Gunderson L.L., Jessup J.M., Martenson J.A. 2001. Chemoradiotherapy after surgery compared with surgery alone for adenocarcinoma of the stomach or gastroesophageal junction. $N$ Engl J Med, 345:725.

Mari E, Floriani I., Tinazzi A., Buda A., Belfiglio M., Valentini M., Cascinu S., Barni S., Labianca R., Torri V. 2000. Efficacy of adjuvant chemotherapy after curative resection for gastric cancer: a metaanalysis of published randomised trials. A study of the GISCAD (Gruppo Italiano per lo Studio dei Carcinomi dell'Apparato Digerente). Ann Oncol, 11(7):837-43.

Moertel C.G., Childs D.S., O’Fallon J.R., Holbrook M.A., Schutt A.J., Reitemeier R.J. 1984. Combined 5fluorouracil and radiation therapy as a surgical adjuvant for poor prognosis gastric carcinoma. J Clin Oncol, 2(11):1249- 54.

Öksüz D.Ç., Eren M.F., Beşe N.Ş., Büyükünal E., Özgüroğlu M., Mandel N.M., Turna H., Demirelli F., Erdengeçti S., Atkovar G., ÖBER A. 2010. Mide karsinomlarında postoperatif kemoradyoterapi tedavi sonuçları: Cerrahpaşa deneyimi. Türk Onkoloji Dergisi, 25(1):1-10.

Sasako M., Sakuramoto S., Katai H., Kinoshita T., Furukawa H., Yamaguchi T., Nashimoto A., Fujii M., Nakajima T., Ohashi Y. 2011. Five-year outcomes of a randomized phase III trial comparing adjuvant chemotherapy with S-1 versus surgery alone in stage II or III gastric cancer. J Clin Oncol, 29:4387. 